\title{
Corpus
}

Archivos virtuales de la alteridad americana

Vol 1, No 2 | 2011

Julio / Diciembre 2011

\section{El genocidio en la historia: ¿Un anacronismo?}

\section{Florencia Roulet and María Teresa Garrido}

\section{OpenEdition}

\section{Journals}

Electronic version

URL: http://journals.openedition.org/corpusarchivos/1159

DOI: 10.4000/corpusarchivos. 1159

ISSN: 1853-8037

\section{Publisher}

Diego Escolar

\section{Electronic reference}

Florencia Roulet y María Teresa Garrido, «El genocidio en la historia: ¿Un anacronismo? », Corpus [En línea], Vol 1, No 2 | 2011, Publicado el 30 diciembre 2011, consultado el 19 abril 2019. URL : http:// journals.openedition.org/corpusarchivos/1159; DOI : 10.4000/corpusarchivos.1159

This text was automatically generated on 19 April 2019.

Licencia Creative Commons: Atribución-NoComercial 2.5 Argentina (CC BY-NC 2.5 AR) 


\title{
El genocidio en la historia: ¿Un anacronismo?
}

\author{
Florencia Roulet and María Teresa Garrido
}

\section{A la memoria de Pedro Navarro Floria}

1 La aplicación del concepto de genocidio a la política seguida por el Estado argentino republicano contra los pueblos indígenas libres de la Pampa, la Patagonia y el Chaco suscita a menudo vivas objeciones. La primera consiste en afirmar que, so pena de anacronismo, no se puede usar una noción jurídica consagrada en 1948 por las Naciones Unidas para describir hechos acontecidos varias décadas antes.

2 La segunda pretende que, en un contexto intelectual marcado por el darwinismo social que afirmaba la superioridad de la raza blanca y su derecho a someter a las demás por la fuerza, los responsables de la política estatal no habrían tenido consciencia de cometer delito alguno. En toda legalidad, no habrían hecho sino acelerar artificialmente el proceso natural de la "inevitable" extinción de las "razas inferiores" y su sustitución por la raza blanca.

3 La tercera supone que, en la medida en que no se llevó a cabo la completa desaparición de los pueblos indígenas, no se puede hablar de genocidio.

Pretendemos desvirtuar estos argumentos desarrollando tres ejes de análisis. Quisiéramos determinar en primer lugar si las prácticas que afectaron a la población indígena durante el proceso de expansión del Estado nacional sobre los territorios y sociedades de los pueblos originarios caben en la actual definición de genocidio. Nos interrogaremos enseguida sobre las nociones jurídicas vigentes en el siglo XIX para evaluar si esos actos o algunos de ellos constituían entonces un delito de lesa humanidad. Concluiremos con una reflexión acerca de si es jurídicamente adecuado y útil hoy calificar aquellos hechos como genocidio. 


\section{Crimen de genocidio y delito de lesa humanidad}

5 Considerado por la Asamblea General de las Naciones Unidas como un "odioso flagelo" que "en todos los períodos de la historia ha infligido grandes pérdidas a la humanidad", el genocidio fue definido jurídicamente en 1948 como un conjunto de actos "perpetrados con la intención de destruir, total o parcialmente, a un grupo nacional, étnico, racial o religioso, como tal". Esos actos son: la matanza de miembros del grupo; la lesión grave a la integridad física o mental de los miembros del grupo; el sometimiento intencional del grupo a condiciones de existencia que acarreen su destrucción física, total o parcial, las medidas destinadas a impedir los nacimientos en el seno del grupo y el traslado por la fuerza de niños del grupo a otro grupo ${ }^{1}$.

6 En la medida en que estos actos de exterminio son cometidos de modo sistemático y premeditado contra una población civil, constituyen un delito de lesa humanidad. Es decir, un crimen que por su naturaleza horrenda agravia, lesiona y ofende a la humanidad en su conjunto ${ }^{2}$. Si bien el derecho internacional brinda tardíamente una definición que abarca -entre otros- los actos de asesinato, exterminio, esclavitud, deportación o traslado forzoso, encarcelación ilegal, tortura, violación y prostitución forzada, la noción de crimen contrario a la humanidad es antigua. La evocaba por ejemplo el virrey Vértiz, para quien el degüello de indias ancianas era una práctica "repugnante a la humanidad por más razones que quieran alegarse en contrario"3.

7 ¿Correspondieron las políticas estatales republicanas argentinas hacia los pueblos indígenas a las modernas definiciones de genocidio y crimen de lesa humanidad? Veamos en primer lugar las metas que éstas perseguían. Como las campañas previas de Martín Rodríguez y de Juan Manuel de Rosas, la del ministro de guerra Julio Argentino Roca tenía como objetivo "extirpar el mal de raíz y destruir esos nidos de bandoleros que incuba y mantiene el desierto" (Roca 1948, p.454)4. Si el discurso oficial proponía "buscar al indio en su guarida, para so-meterlo o expulsarlo" al sur del río Negro -desalojando así quince mil leguas cuadradas de tierras (Roca 1948, pp.445 y 455)-, extraoficialmente se hablaba de exterminio, lo que entonces como ahora significaba "expulsión o destierro; desolación, destrucción total de alguna cosa" (RAE 1869, p.349; el subrayado es nuestro). Ignacio Fotheringham, que fuera ayudante y secretario de Roca cuando éste se desempeñaba como Comandante en Jefe de la frontera sur de Córdoba, cuenta sin falsos pudores cómo preparaba ya entonces su jefe sus "proyectos audaces sobre el exterminio de los indios" (Fotheringham 1970, p.373, 301 y 441). Y el propio Roca afirmaba que el "mejor sistema de concluir con los indios, ya sea extinguiéndolos o arrojándolos al otro lado del Río Negro" era "el de la guerra ofensiva" y se ufanaba, ya concluida la campaña, de haber "hecho desaparecer las numerosas tribus de la Pampa que se creían invencibles" (Walther 1948, II, p.218, 250).

8 Consideremos en segundo lugar los métodos utilizados. Como en todas las guerras, era lógico que en la lucha se intentara poner fuera de combate a un máximo de enemigos armados. Sin embargo, ésta no fue la táctica adoptada. Más que la batalla frontal, se procuró la detención, dispersión y servidumbre de las mujeres e hijos de los indios para impedir su perpetuación como grupo; la captura de sus ganados y demás bienes para obligarlos a rendirse y la apropiación definitiva de los territorios que ocupaban. "Los indios -preconizaba el general Alvaro Barros, uno de los ideólogos de la campaña al desierto-, serían aniquilados si no cayendo inmediatamente en nuestro poder los hombres 
[...] cayendo irremediablemente sus familias y cuanto allí tuviesen". Además de ser los objetos que estos más amaban, las familias y ganados de los indios resultaban "indispensables a su existencia". Sin ellos, "antes que morir de hambre en la selva, [el indio] vendrá cabizbajo y convencido" (Barros 1975, pp. 108, 112, 207-208). La captura de la población no combatiente y el despojo de sus principales medios de subsistencia no eran, pues, el resultado colateral de las operaciones sino el principal método de las tropas en campaña.

Una vez obtenida la victoria se debía acabar con el in-dio como tal desarticulando su organización social, política y económica para impedirle perpetuar su cultura, obligando a los sobrevivientes a subsumirse individual-mente en los estratos inferiores del proletariado rural. El destino que les esperaba era presentado en términos que Pedro Navarro Floria calificaba como "uno de los más persistentes sofismas constitutivos del discurso de la conquista: la idea de que se podría incorporar esos territorios a la Nación sin afectar a sus habitantes" (Navarro Floria 2006, p. 9). Un claro ejemplo de ese sofisma se encuentra en la prosa de Alvaro Barros. Si bien proponía "hacer desaparecer", "aniquilar", "suprimir", "extinguir", "ultimar", "someter", "dispersar" y "absorber" al indio mediante el mestizaje, procuraba con una pirueta retórica que su proyecto no fuera rotulado como exterminio ${ }^{5}$ :

Estamos contra la idea del exterminio de los indios, por ser esto más que innecesario inconveniente, injusto y bárbaro, pero estamos también contra la idea de conservarlos reunidos, ya sea en poblaciones especiales con autoridades propias, ya en cuerpos militares especiales también. Bajo una $u$ otra forma ellos pudieran conservar y conservarían su carácter distintivo, su espíritu y sus hábitos de independencia [...]. La absorción es el único medio seguro, justo, económico y bajo todo punto de vista ventajoso, que tenemos de acabar con los indios, mezclándose esta raza con la inmigración europea como se ha hecho en toda la América desde el principio de la conquista. (Barros 1975, p. 229)

11 El mestizaje que preconizaba Barros no era una libre unión de indios e indias con inmigrantes de ambos sexos sino, como se había hecho en efecto desde principios de la conquista, la sumisión forzada y a menudo violenta de las indias a los hombres blancos. Durante la campaña propiamente dicha, las prisioneras eran obligadas a seguir a sus captores a marcha acelerada. Las que no podían sostener el ritmo eran lanceadas. Las que aguantaban eran finalmente repartidas entre los soldados (Prado 1942, p. 125, 126). Los partes de guerra no mencionan el lado sucio de estos repartos -las violaciones y otros abusos- sugiriendo incluso que las propias indias consentían en la nueva suerte que les cabía o negando que hubiera intenciones de aprovecharse sexualmente de ellas ${ }^{6}$. Sin embargo, como en todos los tiempos, estas prácticas eran moneda corriente. Uno de los pocos testimonios explícitos con que contamos es el relato del ex-cautivo Santiago Avendaño que narra cómo, durante una incursión de las tropas rosistas a los toldos ranquelinos, los soldados se habían emboscado junto a las aguadas esperando que las mujeres se acercaran a llenar sus odres vacíos.

Los soldados desenfrenados atropellaron a las chinas que temblaban de terror. Echando pie a tierra, les quitaron cuanto tenían sobre el cuerpo y cometieron toda clase de violaciones y de excesos brutales. Todas fueron conducidas al campamento, donde sufrieron el doble de vejámenes, porque se vieron pasar de mano en mano y en poder de los hombres 'cristianos' más deshonestos, más brutos y más obscenos que podían haber conocido. (Hux 1999, pp. 129-130). 
Captura de familias, confiscación de bienes necesarios a la supervivencia colectiva, desmembramiento de grupos familiares, desarticulación de comunidades, violaciones, esclavitud sexual: los actos cometidos contra las poblaciones indígenas durante su forzada incorporación al Estado republicano constituyen, sin lugar a dudas, delitos enmarcados en los conceptos contemporáneos de genocidio y de crimen de lesa humanidad.

\section{Derecho de gentes y derecho de la guerra en los siglos XVIII y XIX}

Ahora bien, considerando el carácter históricamente contingente de toda formulación jurídica, ¿eran delictivas estas conductas según la doctrina jurídica occidental vigente en la Argentina republicana? ¿Cómo calificaba el derecho de la época una guerra que buscaba el exterminio del contrincante y adoptaba como método la captura de la población civil, su traslado forzado, su dispersión y su esclavitud? ${ }^{7}$

En la mentalidad jurídica rioplatense estuvo vigente hasta entrado el siglo XIX el marco doctrinario del derecho de gentes elaborado por los juristas Samuel Puffendorf (Alemania, 1632-1694), Christian Wolff (Alemania, 1679-1754) y Emer de Vattel (Suiza, 1714-1767) sobre la base de los escritos de Hugo Grocio (Holanda, 1583-1645). Los trabajos de estos tratadistas eran difundidos en la Universidad de Buenos Aires por su primer rector, Antonio Sáenz ${ }^{8}$. Aunque aún sin carácter obligatorio, esa doctrina se refería también a las costumbres observadas por los Estados europeos durante las hostilidades, tales como las treguas destinadas a recoger cadáveres y a asistir enfermos 9 .

Para estos teóricos, las prácticas de la guerra entre Estados soberanos debían ajustarse a las nociones de necesidad militar y de proporcionalidad. "Todo lo que se haga de más es reprobado por la Ley Natural, vicioso \& condenable ante el Tribunal de la Conciencia". La integridad del enemigo que se sometía y rendía las armas debía ser preservada a menos que hubiera cometido un grave crimen contra el derecho de gentes, en cuyo caso podía ser esclavizado o ejecutado. Pero en el caso de una guerra contra "naciones feroces que no observan ninguna regla ni dan cuartel" era legítimo castigarlas en la persona misma de los cautivos que pudieran conseguir-se, para someterlos a las "leyes de la humanidad". Con estas naciones "que parecen nutrirse de los furores de la Guerra", haciéndola sin otro pretexto o motivo que su ferocidad, era válido incluso recurrir al exterminio, ya que se trataba de "monstruos, indignos del nombre de hombres [que] deben ser mirados como enemigos del género humano" (Vattel 1983, p. 27, 106-108).

Esta licencia para el exterminio inspiró a los hombres de Estado que en el siglo XIX, al norte como al sur del continente americano, se proponían ocupar los territorios indígenas vaciándolos previamente de indios. En un largo proceso de elaboración discursiva que tenía como finalidad la afirmación de soberanía estatal sobre territorios y pueblos hasta entonces pertinazmente externos a las repúblicas en gestación fue cobrando forma un mito que echaría honda raíz en el imaginario colectivo ${ }^{10}$. Según él, las naciones originarias soberanas con quienes los Estados coloniales y republicanos habían firmado trata-dos de paz hasta la década de 1870, no constituían sino hordas de salvajes morando en desiertos más allá de una "frontera interior" que amputaba al país una parte sustancial de los territorios que por derecho le pertenecían. Reducidas a meras corporaciones civiles, se las privaba de un plumazo de personería jurídica internacional. Un elemento central de este mito es la caracterización de los indios como salvajes sanguinarios que 
hacen de la guerra y la rapiña un modo de vida ${ }^{11}$. La ferocidad indígena se volvía necesaria y funcional a la legitimación de la guerra colonial ${ }^{12}$. De la empresa propagandística que consagró el mito del "Salvaje Innoble" (Jennings 1975, p. 59) se encargarían estrategas, publicistas y la naciente historiografía nacional: "la conquista de la memoria fue uno de los movimientos tácticos que formaron parte de la apropiación imaginaria de la Pampa y la Patagonia, que posibilitó a su vez su conquista material manu militari, entre 1875 y 1885" (Navarro Floria 2005).

17 Frente a la construcción de ese mito que llevaba a pos-turas extremas como las de Domingo F. Sarmiento ${ }^{13}$, se alzaron sin embargo algunas voces críticas que preanunciaban el discurso que se iría imponiendo en la segunda mitad del siglo, a saber que la "civilización" daba no sólo derechos sobre los pueblos "salvajes" juzgados inferiores sino un deber de tutela y protección que excluía la opción del exterminio ${ }^{14}$. En 1865, el historiador Vicente Quesada condenaba la campaña al desierto de Rosas en duros términos:

Nada estable se funda sobre la iniquidad, y el propósito de exterminar [a] los indios es un crimen, cuya sangre es ignominia para nuestras armas. Someterlos y atraerlos a los usos blandos de la civilización, mejorarlos y conquistarlos para el bien, ése es el único camino justo y digno" (Quesada 1865, pp. 48-49).

En la Revista del Río de la Plata del 22 de agosto de 1869, su contemporáneo, el escritor y legislador José Hernández, coincidía:

Nosotros no tenemos el derecho de expulsar a los indios del territorio y menos de exterminarlos. La civilización sólo puede darnos derechos que se deriven de ella misma [...]

¿Pero qué civilización es ésa que se anuncia con el ruido de los combates y viene precedida del estruendo de las matanzas? (Hernández 1869).

Hasta el propio Julio A. Roca -respondiendo a la inquietud de que se procurara "dominar a los indios por medios pacíficos" porque no convenía "extinguir esa raza, que representa la soberanía de la Nación en el desierto"-, debió aclarar que "no hay ningún propósito de exterminar la raza". De ello se encargaría "esa ley del progreso y de la victoria, por la cual la raza más débil, la que no trabaja, tiene que sucumbir al contacto de la mejor dotada, ante la más apta para el trabajo". Los indios de la Argentina no desaparecerían por el filo de la espada sino "por la absorción y asimilación". ${ }^{15}$

Esta evolución de las mentalidades en Argentina acompañaba el desarrollo del pensamiento jurídico occidental con respecto a la guerra. Se impone en la segunda mitad del siglo XIX una dinámica tendiente a humanizar los usos bélicos, que llevará a la creación del Comité Internacional de la Cruz Roja (1863) y a los primeros esfuerzos de reglamentación del derecho de la guerra. En Estados Unidos, el Código de Lieber elaborado durante la guerra de la Secesión aparecía como la primera tentativa de codificación de las leyes de la guerra, de aplicación exclusivamente interna ${ }^{16}$. Siguió enseguida la Convención multilateral para mejorar la suerte de los militares heridos en campaña (I Convenio de Ginebra), que la Argentina ratificó en 1879. En paralelo a esos instrumentos de cumplimiento obligatorio se fueron desarrollando declaraciones de principio que fundan la doctrina del actual derecho internacional humanitario ${ }^{17}$. Principios como que "el único fin legítimo de la guerra es el debilitamiento de las fuerzas militares del enemigo" para lo cual basta con "desactivar el mayor número posible de hombres" y que "las leyes de la guerra no reconocen a los beligerantes un poder ilimitado en la adopción de me-dios para perjudicar al enemigo" fueron consagrados ya en la década de 1860. El empleo de armas que agravaran inútilmente el sufrimiento del 
enemigo puesto fuera de combate o que causaran inevitablemente su muerte era considerado "contrario a las leyes de la humanidad". ${ }^{18}$

Creado en 1873 en Gantes (Bélgica), el Instituto de Derecho Internacional redactó un Manual de las leyes de la guerra terrestre que serviría como base para la elaboración de la legislación interna de cada Estado. La doctrina sentada en estos primeros textos prohibía el asesinato de un enemigo desarmado o que se hubiera rendido. Como prisionero de guerra, debía ser tratado humanamente: aunque se lo internara en un fuerte u otro lugar de detención, debía ser correctamente alimentado, respetado en su integridad física y retribuido por los trabajos civiles que realizara. Estaba prohibido ponerlo al servicio militar de la fuerza detentora y exigirle información militar sobre su país. En cuanto a la población civil no combatiente, su vida, su honor familiar, así como sus convicciones y prácticas religiosas debían ser garantizados. La población de las regiones invadidas no podía ser obligada a jurar obediencia a la potencia enemiga ni a someterse a sus órdenes. La propiedad privada tampoco podía ser confiscada. Respecto de los medios y los métodos de hacer la guerra, la doctrina prohibía la destrucción o apropiación de los bienes del enemigo que no fuera imperiosamente dictada por las necesidades de la guerra, lo mismo que el ataque o bombardeo de aglomeraciones o poblaciones no fortificadas.

Este marco doctrinario y normativo muestra a las claras que las prácticas empleadas en particular durante la campaña al desierto -captura de población no comba-tiente, su traslado forzado, dispersión, distribución y reducción a la servidumbre, su involuntaria conversión al catolicismo y los abusos sexuales contra las mujeres, así como la utilización de prisioneros de guerra desarmados como guías e informantes, su detención en campos de concentración y su ejecución arbitraria (cf. Lenton 2005 y Delrio 2005)- eran violatorias de lo que entonces se entendía como "leyes de la guerra" y "leyes de la humanidad" y contrarias al "deber sagrado de civilización" que se atribuían a sí mismas las potencias coloniales y sus retoños en los países independientes. Así fueron percibidas por varios observadores contemporáneos:

Veinte mil leguas de tierra arrancadas a la barbarie y de-vueltas a la civilización y algunos miles de Indios traidos prisioneros y repartidos a diferentes personas como si fueran animales de labranza, he ahí el resultado de la campaña" (Zavalía 1892, p. 80).

En cambio de los tan mentados "beneficios de la civilización" se advierte un proyecto coherente de exterminio que, si no busca sistemáticamente la eliminación física de los indios, se empeña en liquidar su existencia como pueblos y en acaparar sus tierras, buscando sentenciar a muerte sus modos de vida, culturas e identidades específicas.

\section{Para qué hablar hoy de genocidio}

¿Es válido entonces calificar de genocidio al proceso derivado de la conquista de la Pampa y la Patagonia entre 1875 y 1885 ?

26 La consagración jurídica de los conceptos que designan prácticas delictivas siempre es posterior a la generalización de su uso, ya que el delito precede al concepto y éste precede al tipo penal. Lo reciente del término genocidio no debe hacernos olvidar que se trata de un nuevo nombre para un crimen tan viejo como el mundo. Neologismo elaborado en 1943 por el jurista polaco Raphael Lemkin (1900-1959) para describir el exterminio sistemático de armenios por el Estado turco en 1915, el concepto de genocidio fue formalmente invocado en el acta de acusación contra los criminales de guerra nazis 
juzgados en Nuremberg en 1946, antes de ser tipificado por la Convención para la Prevención y la Sanción del Delito de Genocidio en $1948^{19}$. Afirmar que la política del Estado republicano argentino hacia los indígenas constituyó un genocidio no constituye, pues, un anacronismo, sino simplemente llamar a las cosas por su nombre.

Dicho esto, ¿qué se puede hacer hoy, ante un genocidio de ayer? Tomando prestados conceptos de la teoría de la justicia transicional y sirviéndonos de los elementos pertinentes de los convenios y declaraciones vigentes relativos a los pueblos indígenas podemos explorar las posibilidades actuales de reconocimiento y de reparación. ${ }^{20}$

Tres elementos integran la justicia transicional: justicia, verdad y reparación integral. La justicia puede ser retributiva -la que busca el castigo de los criminales- o restaurativa -un modelo alternativo que propende a la reconciliación entre víctimas y victimarios. La verdad puede ser judicial -la que se establece a través de un proceso penal- o no judicial es decir, la narración que sale de las ciencias sociales y de las experiencias vividas por las mismas comunidades victimizadas. En cuanto a la reparación integral, se manifiesta a través de medidas de restitución, de indemnización, de rehabilitación y de satisfacción, así como a través de garantías de no repetición.

En tanto aproximación esencialmente penal -considerando que la pena es individual e intransferible- resulta físicamente imposible aspirar hoy a obtener cualquier forma de justicia retributiva respecto de las personas responsables de los crímenes cometidos entonces. Tampoco es ya posible aspirar a la justicia restaurativa, en la medida en que, así como los victimarios, las víctimas directas individualmente consideradas, también están ausentes.

Las posibilidades empiezan a abrirse, en cambio, en el campo de la verdad. Si no es posible establecer hoy la verdad judicial, la ausencia física de los actores no obstruye para nada las posibilidades de la verdad no judicial. Las víctimas en su dimensión colectiva, es decir los descendientes y la sociedad en su conjunto, tienen un derecho inalienable a conocer toda la verdad sobre los acontecimientos. Esto es, en particular, a obtener información sobre las circunstancias y motivos que llevaron a los victimarios a cometer crímenes aberrantes y a saber de qué manera se produjeron los hechos, quiénes fueron los responsables y qué destino se dio a las personas. ${ }^{21}$ En este sentido, la labor de historiadores, antropólogos y arqueólogos que en los últimos años analizan los mecanismos que hicieron posible el genocidio y deconstruyen los mitos generados para justificarlo resulta de particular trascendencia. Esos trabajos deberían nutrir los manuales escolares y el debate público en los medios, revertiendo la práctica usual en dichos manuales de deshistorizar o arqueologizar discursivamente a las naciones indígenas al presentarlas como objetos de un pasado remoto cuyo lugar está en los museos y al excluirlas de la representación de nuestro presente. "Una reconstrucción de la memoria social sobre la cuestión indígena, y por consiguiente una propuesta de enseñanza de esa historia, deberían comenzar por [...] rehistorizar lo dehistorizado, es decir restituir el régimen de historicidad, de contemporaneidad, a los pueblos originarios" (Navarro Floria 2006, p. 4, resaltado del autor). Fuera del marco académico es también fundamental producir verdades sociales no institucionalizadas, mediante ejercicios de recuperación de la memoria que asocien a diferentes organizaciones indígenas, ONGs, comisiones de la verdad, iglesias, medios de comunicación y centros de investigación y educación popular. La verdad así reconstituida transforma el patrimonio colectivo de las víctimas y del conjunto de la sociedad. Estos ejercicios deben permitir asimismo re-pensar los guiones 
museográficos y la nomenclatura urbana, concebir espacios públicos de homenaje, restituir topónimos, adoptar fechas conmemorativas, etc.

Si bien varios aspectos de la reparación integral no parecen ya factibles por la desaparición física de las víctimas individuales, "una indemnización justa, imparcial y equitativa, por las tierras, los territorios y los recursos que tradicionalmente hayan poseído u ocupado o utilizado de otra forma y que hayan sido confiscados, tomados, ocupados, utilizados o dañados sin su consentimiento libre, previo e informado" en favor de los descendientes es aún viable (Declaración de las Naciones Unidas sobre los derechos de los pueblos indígenas, art. 28.1). En cuanto a la rehabilitación y a la satisfacción, varios de sus aspectos son posibles, en particular lo concerniente a la reputación y al nombre, es decir a la dignidad. ${ }^{22}$ Un aspecto especial de la rehabilitación cuyo marco jurídico está dado por el Convenio 169 de la Organización Internacional del Trabajo de 1989 y por la mencionada Declaración se concretaría a través de la institucionalización de la enseñanza bilingüe, del fomento de escuelas concebidas y manejadas por las propias comunidades, amén de otras iniciativas de divulgación e integración de diversos aspectos del conocimiento de cada pueblo. ${ }^{23}$

Adicionalmente, la rehabilitación y la satisfacción comportan los mecanismos de divulgación y de oficialización ante la colectividad nacional de la verdad no judicial obtenida. Un discurso historiográfico que restituyera la historicidad y contemporaneidad de las naciones indígenas en la Argentina actual debería rehumanizar la imagen de los indígenas considerándolos "actores socia-les en todos los campos de la economía, la sociedad, la política, el arte y el pensamiento”. Esa nueva narración del pasado contribuiría asimismo a completar los avances constitucionales de la reforma de 1994 reconociendo la preexistencia de los derechos territoriales indígenas y su exterioridad a los Estados hasta su conquista, así como la preexistencia y legitimidad de sus autoridades y su derecho a la libre determinación (Navarro Floria 2006, pp. 7-8), tal como lo consagran las normas internacionales mencionadas. ${ }^{24}$ Leyes de reconocimiento oficial del genocidio, a la imagen de la ley argentina 26.199 del 2007 sobre el genocidio armenio, pueden servir de referencia. Tal reconocimiento implica que el Estado acepta que los hechos sucedieron, asume su responsabilidad histórica por el dolor y los sufrimientos infligidos a las víctimas, que condena explícitamente los valores racistas en que se fundó el genocidio y que se compromete a luchar contra la ideología de la negación y a favor de la dignidad humana. Volver a llamar a las cosas por su nombre sería "una forma -limitada pero indispensable-de revertir el genocidio material y simbólico cometido" (Navarro Floria 2006, p. 7). Persistir en el no reconocimiento equivale a perpetuar el delito y abre las puertas a la reiteración de esos mismos actos aberrantes:

Si la dignidad de la persona humana es ultrajada por la ejecución de crímenes contra la humanidad y genocidios, sean cuales fueren, también lo está por la negación de es-tos mismos crímenes -el negador hace al testigo lo que el verdugo hace a la víctima. [...] Consubstancial' a los crímenes de los que se trata, su negación no es un acto 'aparte', es 'part of it': 'asesinato de la memoria', 'atentado a la verdad', destrucción de la prueba y del testimonio ligada intrínsecamente a la criminalidad del Estado, la negación es considerada generalmente como la etapa última de todo proceso genocida. Perpetúa el crimen, manteniendo a los sobrevivientes y a sus descendientes en la vergüenza, sin real acceso al duelo. (Garibian 2009, p. 11).

Este reconocimiento público puede verse también como una primera garantía de no repetición, último elemento de la reparación integral que nos queda por examinar. Se 
trata de desmontar los mecanismos que hicieron posible la comisión de los crímenes y de aquellos que aseguraron su impunidad, así como de revisar los actos institucionales que glorificaron esa gesta o negaron sus dramáticas consecuencias para los pueblos originarios. El ejercicio de este aspecto de la reparación podría enfocarse en el estudio de la situación actual de las poblaciones indígenas, de la legislación que se aplica a ellas y de las políticas de inversión pública y privada que afectan sus condiciones de vida, a la luz de los instrumentos jurídicos internacionales relativos a los derechos pasados, presentes y futuros de esos pueblos (cf. en particular el art. 4 y la Parte II., "Tierras" del Convenio 169/89 y los arts. 10 y 25 a 32 de la Declaración del 2007). Los recientes conflictos derivados del recrudecimiento de los procesos de expropiación por intereses mineros, forestales, turísticos y de agronegocios son reveladores de un lega-do de injusticias y despojos siempre vigente, amparado en la prepotencia que brinda la impunidad (cf. Roulet 2010). El presente nos ofrece así un terreno propicio para reflexionar sobre el legado de la historia y para no perpetuar bajo nuevas formas los horrores del pasado.

\section{BIBLIOGRAPHY}

Barros, A. (1975). Indios, fronteras y seguridad interior. Buenos Aires: Solar/Hachette.

Comisión Colombiana de Juristas -CCJ- (2007). Principios internacionales sobre impunidad y reparaciones, compilación de documentos de la ONU. Bogotá: $\mathrm{CCJ}$.

Convenio 169 de la OIT sobre pueblos indígenas y tribales en países independientes (1989). en http://www. ilo.org/public/spanish/region/ampro/lima/publ/ conv-169/convenio.shtml.

Declaración de las Naciones Unidas sobre los derechos de los pueblos indígenas (2007), en http:// www. un.org/esa/socdev/unpfii/es/drip.html.

Delrio, W. (2002). Indios amigos, salvajes o argentinos. Procesos de construcción de categorías sociales en la incorporación de los pueblos originarios al Estado-nación (1870-1885), en Nacuzzi, L. (Comp.). Funcionarios, diplomáticos, guerreros. Miradas hacia el otro en las fronteras de Pampa y Patagonia (siglos XVIII y XIX) (pp. 203-245). Buenos Aires: Sociedad Argentina de Antropología

Delrio, W. (2005). Memorias de expropiación. Sometimiento e incorporación indígena en la Patagonia, 1872-1943. Bernal: Universidad Nacional de Quilmes.

Fotheringham, I. (1970). La vida de un soldado o reminiscencias de las fronteras, I parte. Buenos Aires: Círculo Militar.

Garibian, S. (2009). Derecho, Historia, Memoria. El negacionismo: ¿ejercicio de una libertad o violación de un derecho?, en http://www.cna.org.ar/wp-content/ uploads/2010/03/Negacionismo-SevaneGaribian. pdf .

Hux, M. (1999). Memorias del ex-cautivo Santiago Avendaño. Buenos Aires: Elefante Blanco.

Jennings, Francis (1975). The Invasion of America. Indians, Colonialism and the Cant of Conquest. New York/London: W.W. Norton. 
Lenton, D. (2005). La “cuestión de los indios" y el genocidio en tiempos de Roca: sus repercusiones en la prensa y la política. Ponencia presentada en el Tercer encuentro de 'La Historia de Nosotros': Genocidio y pueblos indios en los medios de comunicación. Comisión de Cultura Bloque 19 y 20 , Legislatura de la Ciudad Autónoma de Buenos Aires, 14.10.2005.

Marfany, R. (1944). La guerra con los indios nómadas. En Levene, R., Historia de la Nación Argentina, VI, pp. 1041-1086. Buenos Aires: Academia Nacional de la Historia.

Navarro Floria, P. (2005). La conquista de la memoria. La historiografía sobre la frontera sur argentina durante el siglo XIX. Universum (Universidad de Talca), 20-1, 88-111, http:// www.scielo.cl/scielo.php?pid=S0718-23762005000100007\&script=sci_arttext .

Navarro Floria, P. (2006). El debate historiográfico sobre la conquista de la Patagonia en el contexto de la democracia argentina post-dictadura. Ponencia presentada en las 2as. Jornadas de Historia de la Patagonia. General Roca, noviembre del 2006, http://www.hechohisto-rico.com.ar/ Trabajos/Jornadas\%20de\%20Roca\%20 -\%202006/NavarroFloria\%28El\%20debate\%29.pdf

Orozco Abad I. (2009). Justicia transicional en tiempos del deber de memoria. Bogotá: Universidad de los Andes y Editorial Temis.

Prado, M. (1942). La guerra al malón. Buenos Aires: Editorial Americana.

Quesada, V. G. (1865). Las fronteras y los indios. Apuntes históricos. La Revista de Buenos Aires, vol. VI, pp. 39-64.RAE (1869). Diccionario de la lengua castellana por la Real Academia Española, 11ª. edición. Madrid: Imprenta de don Manuel Rivadeneyra.

Roca, J.A. (1948). Mensaje y proyecto del Ministro de Guerra Julio A. Roca al Congreso Nacional el 14.8.1878, en Walther, J. C., La conquista del desierto, vol. II. Bue-nos Aires: Círculo Militar, pp. 445-455.

Roulet, F. y P. Navarro Floria (2005). De soberanos externos a rebeldes internos: la domesticación discursiva y legal de la cuestión indígena en el tránsito de los siglos XVIII al XX. TEFROS vol. 3, n 1, http://www.tefros. com.ar/revista/v3n1p05/completos/soberanosext. pdf

Roulet, F. (2010). Volviendo a erigir fronteras. La ofensiva mediática contra los pueblos originarios de Argentina. Nostromo. Revista Crítica Latinoamericana, 3. México: Universidad Nacional Autónoma de México, http:// www.nostromoediciones.net/web/images/stories/ numeros_revista/numero_3/nudos/volviendo_a_erigir_fronteras.pdf

Sáenz, A. (1939). Instituciones elementales sobre el Derecho natural y de gentes. Buenos Aires: Instituto de Historia del Derecho Argentino, Facultad de Derecho y Ciencias Sociales.

Sarmiento, D.F. (1990). Facundo. Civilización y Barbarie. Madrid: Cátedra.

Snow, A. (1919). The Question of Aborigines in the Law and Practice of Nations. Washington: Government Printing Office.

Uprimny R.et al. (2006). ¿Justicia transicional sin transición? Verdad, justicia y reparación para Colombia. Bogotá: Centro de Estudios de Derecho, Justicia y Sociedad (DeJuSticia).

Vattel, E. de (1983). Le droit des Gens ou Principes de la Loi Naturelle appliqués à la conduite et aux affaires des Nations et des Souverains, ed. facsimilar, Slatkine reprints. Ginebra: Henry Dunant Institute.

Williams, R.A. (1992). The American Indian in Western Legal Thought. The Discourses of Conquest. New York: Oxford University Press.

Zavalía, E. (1892). Los indios ante la Constitución y las leyes. Buenos Aires: ed. del autor. 


\section{NOTES}

1. Artículo II de la Convención para la prevención y la sanción del delito de genocidio de las Naciones Unidas.

2. Para la definición del delito de lesa humanidad, véase el artículo 7 del Estatuto de Roma de la Corte Penal Internacional, de 1998.

3. Carta de Juan José de Vértiz a Joseph Francisco de Amigorena, 10.5.1780, en Archivo Histórico de Mendoza, carpeta 46, documento 23. En 1892, el jurista argentino Eduardo Zavalía usaba la noción de "crímenes de lesa humanidad" para referirse a los abusos, maltratos, explotación laboral y despojos a los que habían sido sometidos los indígenas por los conquistadores españoles (Zavalía 1892, p. 48).

4. En 1823 el gobernador bonaerense Martín Rodríguez afirmaba su proyecto de exterminio: "La experiencia de todo lo hecho [...] nos guía al convencimiento de que la guerra con ellos debe llevarse hasta el exterminio. Hemos oído muchas veces a genios más filantrópicos la susceptibilidad de su civilización e industria y lo fácil de su seducción a la amistad. Sería un error permanecer en un concepto de esta naturaleza y tal vez perjudicial" (en Marfany 1944, pp. 1061-1062).

5. Para "hacer desaparecer" al indio, cf. Barros 1975, pp. 77, 230, 235 y 350; "aniquilarlo", pp. 107, 108, 110 y 137; “extinguirlo", p. 248; “suprimirlo”, pp. 138, 150 y 232; “ultimarlo en sus guaridas”, p. 342, "someterlo y dispersarlo", pp. 258, 317, 319, 338 y 359 y "absorberlo" mediante el mestizaje, pp. 229, 249 y 358.

6. Mientras que el comandante Prado relata que ninguna de las prisioneras rehusó vivir con los soldados (Prado 1942, p. 126), el general Ignacio Fotheringham, que veía a los indios del Chaco como "asquerosos tipos todos, aún los del bello sexo", decía que las chinas "son muy feas y por cierto no inducen a cautivarlas" (Fotheringham 1970, p. 569).

7. Adherimos a la hipótesis del jurista Robert A. Williams Jr. según la cual “la ley, considerada por Occidente como su instrumento de civilización más respetado y apreciado, era también el instrumento imperial más vital y eficaz durante su empresa genocida de conquista y colonización de los pueblos no Occidentales del Nuevo Mundo, los indígenas americanos" (Williams 1992, p. 6).

8. Según Antonio Sáenz, el derecho de gentes o jus gentium "es universal y sale de la naturaleza, dándose á conocer solamente por la recta razón [...] Es inalterable [...] y obliga á todos, porque en él habla la naturaleza y su Autor" (Sáenz 1939, p. 57).

9. Estas costumbres serían erigidas en fuentes obligatorias de derecho por el II Convenio de la Haya de 1899 relativo a las leyes y a las costumbres de la guerra terrestre.

10. Este proceso de transferencia gradual de las relaciones con las naciones indígenas del ámbito del derecho internacional al de la legislación interna se de-signa como la "domesticación o internalización de la cuestión indígena" (cf. Roulet y Navarro Floria 2005).

11. De la población indígena no sometida Julio A. Roca diría que "se dedican indistintamente a la guerra y al robo, que para ellos son sinónimos de trabajo" (Roca 1948, p. 451). Sobre el proceso de salvajización discursiva de los pueblos originarios, véase Jennings 1975, pp. 6-10. Para la Argentina, Delrio 2002 y 2005, pp. 61-63 y Roulet y Navarro Floria 2005.

12. En 1820, el coronel Pedro Andrés García advertía “lo perjudicial que será siempre abrir una guerra permanente con dichos naturales, contra quienes parece no puede haber un derecho que nos permita despojarlos con una fuerza armada si no en el caso de invadirnos" (en Barros 1975, pp. 67-68, destacado nuestro).

13. Sarmiento sostenía que el derecho de gentes no se aplicaba a los salvajes, se tratara de caudillos como Facundo o de indios de la pampa: "El derecho de gentes que ha suavizado los horrores de la guerra, es el resultado de siglos de civilización; el salvaje mata a su prisionero, no 
respeta convenio alguno siempre que haya ventaja en violarlo; ¿qué freno contendrá al salvaje argentino [en este contexto, Facundo], que no conoce ese derecho de gentes de las ciudades cultas? ¿Dónde habrá adquirido la conciencia del derecho? ¿En la Pampa?” (Sarmiento 1990, p. 253).

14. La noción de un "deber sagrado de civilización" que-daría consagrada en la Conferencia de Berlín sobre Africa Occidental en 1885, que marcó la aceptación explícita, por parte de las potencias colonizadoras, de una relación legal de tutela entre los "Estados civilizados" y sus pupilos, las "tribus aborígenes" (Snow 1919, p. 21). Esta noción sería retomada en el sistema de mandatos de la Sociedad de las Naciones.

15. República Argentina, Congreso Nacional (1879). Diario de sesiones de la Cámara Nacional de Diputados, $51^{\circ}$ sesión ordinaria del 13.9.1878, p. 256. Buenos Aires: Mayo.

16. Las 'Instrucciones de Lieber' marcaron los intentos ulteriores de codificación de las leyes de la guerra. Ellas integraron la versión original de un proyecto de convenio internacional presentado a la Conferencia de Bruselas en 1874 y estimularon la adopción de los Convenios de la Haya sobre la guerra terrestre de 1899 y de 1907. Estos primeros textos y tratados de derecho internacional humanitario se pueden consultar en http://www.icrc.org/dih .

17. La Argentina fue temprana signataria de la Declaración sobre diversos puntos del derecho marítimo en tiempos de guerra de 1856.

18. Declaración sobre la utilización en tiempos de guerra de proyectiles de 400 gramos de peso, San Petersburgo, 1868 y Proyecto de declaración internacional relativa a las leyes y costumbres de la guerra. Bruselas, 1874 .

19. El acta de acusación de los criminales de guerra juzgados en Nuremberg en 1946 rezaba "los acusados se han hecho culpables de genocidio deliberado y sistemático contra grupos nacionales y raciales, contra las poblaciones civiles de ciertos territorios ocupados, con miras a destruir razas y clases determinadas, y grupos nacionales, raciales o religiosos, más especialmente Judíos, Polacos y Gitanos, entre otros" (Cf. http://www.ladocumentationfrancaise.fr/dossiers/justicepenale-internationale/definition-crimes.sht-ml).

20. La justicia transicional es definida como "los procesos a través de los cuales se realizan transformaciones radicales del orden social y político, bien sea por el paso de un régimen dictatorial a uno democrático, bien por la finalización de un conflicto interno armado y la consecución de la paz." Uno de sus desafíos más complejos es el inevitable dilema que suscita la necesidad de equilibrar el derecho de las víctimas a obtener el castigo de los criminales -justiciay las condiciones impuestas por el régimen dictatorial para permitir la transición o por los actores armados para desmovilizarse -paz- (Uprimny 2006, p.13, 20, Orozco Abad 2009).

21. Estos derechos se derivan de los instrumentos universales y regionales sobre derechos humanos, de las jurisprudencias de las diversas cortes internacionales y de las "líneas de los órganos intergubernamentales de la ONU", condensadas en una serie de principios relativos a la lucha contra la impunidad y a los derechos a la reparación, restitución, indemnización y rehabilitación de las víctimas (Cf. CCJ 2007).

22. La restitución consiste en devolver a la víctima directa su situación previa, es decir libertad, derechos suspendidos, situación social, identidad, vida familiar, ciudadanía, lugar de habitación o puesto de trabajo, bienes confiscados, etc. En caso de desaparición forzada, se trata de establecer la suerte corrida por la víctima. La indemnización atañe a la reparación del daño físico y/o mental así como los daños materiales y los perjuicios. La rehabilitación abarca tanto los aspectos de salud física y/o psicológica, como la rehabilitación del buen nombre, la dignidad, la reputación, entre otros. Por último, la satisfacción se concreta mediante la verificación de los hechos y la difusión pública de la verdad; la búsqueda y hallazgo de las personas desaparecidas o de sus restos; el reconocimiento público de la responsabilidad estatal y la presentación pública de excusas; la aplicación de sanciones judiciales o administrativas a los responsables cuando es 
posible; la conmemoración de las víctimas y la rendición de homenajes públicos (Uprimny 2006, pp. 76 a 78$)$.

23. Véanse en particular los arts. 4 y 5 del Convenio $169 / 89$, y los arts.11 a 14 de la mencionada Declaración.

24. Cf. artículo 3 de la Declaración del 2007 y las disposiciones previstas por esta Declaración y por el Convenio 169 de la OIT acerca de los mecanismos de consulta y de consentimiento previo, libre e informado.

\section{AUTHORS}

\section{FLORENCIA ROULET}

Lic. en Historia, Universidad de Buenos Aires, Argentina.

Correo electrónico: flo.roulet@gmail.com

\section{MARÍA TERESA GARRIDO}

Lic. en Derecho, Universidad Externado de Colombia. Consultora en derechos humanos y en derecho internacional humanitario.

Correo electrónico: tegarrido@hotmail.com 